\title{
os bancos de custeio rural e o crédito agrícola em são paulo (1906-1914)
}

\author{
Fábio Rogério Cassimiro Correa $\star \star$ \\ Mestrando do Programa de Pós-Graduação em História Econômica da Universidade de São \\ Paulo, sob a orientação da $\operatorname{Prof}^{\underline{a}} \operatorname{Dr}^{\underline{a}}$ Marisa Midori Deaecto.
}

\begin{abstract}
RESUMO
Os Bancos de Custeio Rural formaram uma rede de cooperativas de crédito que atuou entre 1906 e 1914 no interior do estado de São Paulo. Esses bancos emprestavam apenas aos fazendeiros associados o valor demandado no financiamento anual da lavoura. Tendo surgido no contexto da crise cafeeira de 1896-1906, a sua reconstituição revela o intenso debate a respeito dos meios de se combater a crise e o papel do Estado no financiamento agrícola. Os bancos de custeio surgiram como uma alternativa à intervenção governamental no sistema de crédito e representam a primeira experiência com o cooperativismo de crédito no estado de São Paulo. Em 1914 eles estavam presentes em quarenta e nove cidades paulistas; no entanto, apesar de seu rápido crescimento eles desapareceram após a falência da companhia que os organizava, em janeiro deste ano. Neste artigo, discutimos as circunstâncias de seu surgimento, sua organização, atuação e falência.
\end{abstract}

Palavras-chave: Crédito Agrícola, Café, Bancos Populares, Cooperativas.

\begin{abstract}
The "Bancos de Custeio Rural" consisted of a network of credit unions that operated between 1906 and 1914 in the state of São Paulo. During this period, these banks lent, to associated farmers only, the necessary amount to fund their annual crop. Having arisen in the context of the coffee crisis of 1896-1906, their reconstitution reveals the intense debate regarding ways to tackle the crisis and the role of the state in agricultural finance. The BCRs emerged as an alternative to government intervention in the credit system and represented the first experience with the credit cooperativism in the state of São Paulo. In 1914, they were present in fortynine cities of that state. However, despite its rapid growth, they disappeared as soon as the company that have organized them went bankrupt, in January of that same year. In this article, we discuss the circumstances of its emergence, organization, operations and bankruptcy.
\end{abstract}

Key-words: Agricultural Credit, Coffee, Popular Banks, Cooperatives.

* Submetido: setembro 2012; aceito dezembro, 2012.

$\star \star$ Esta pesquisa conta com financiamento da FAPESP.Email: fabio.correa@usp.br 
Neste artigo, pretendemos reconstituir a trajetória dos Bancos de Custeio Rural e situá-la no contexto político e econômico da Primeira República.

O tema do financiamento é bastante recorrente na literatura sobre a cafeicultura, embora os estudos específicos sobre este tema tenham se desenvolvido muito recentemente. A questão do financiamento mereceu maior atenção nos estudos relacionados ao período monárquico, principalmente por conta da aquisição de mão de obra, que determinava uma grande imobilização de recursos ${ }^{1}$.

Lembremo-nos da clássica obra de Stanley Stein, Grandeza e Decadência do Café no vale do Paraíba, trabalho publicado em 1959 que, embora tenha abordado o vale do Paraíba fluminense, descreve de forma minuciosa a atuação dos comissários como os principais credores dos cafeicultores, ao lhes conceder adiantamentos em mercadorias e em dinheiro sobre o café que tomariam em consignação para vender no Rio de Janeiro. Além dos comissários, prestamistas locais (os chamados "capitalistas") e grandes fazendeiros também faziam empréstimos garantidos, principalmente, pela hipoteca dos escravos, enquanto que os bancos tendiam a não emprestar diretamente aos fazendeiros, ainda que o fizessem indiretamente através desses intermediários (STEIN, 1961:31-6).

No estudo Homens livres na ordem escravocrata, de Maria Sylvia De Carvalho Franco, a atividade dos comissários mereceu considerações relevantes, tendo sido destacada a sua atuação na concessão do crédito, atividade interpretada pela autora como um arranjo particular de uma economia ainda pouco desenvolvida onde, de um lado, o fazendeiro dependia do crédito fornecido por seu agente comercial e, por outro, os comissários se beneficiavam dessa situação que lhes garantia a fidelidade no fornecimento de café (FRANCO, 1974: 162-4).

Renato Leite Marcondes estudou a cafeicultura no município de Lorena (no Vale do Paraíba paulista) e mapeou a origem e o destino do crédito na região por meio de inventários post mortem (MARCONDES, 1998, cap. V). Em seu estudo, o comissariado do Rio de Janeiro teve importância menor do que fora verificado nas obras citadas anteriormente, mas em contrapartida, ele observou a predominância de presta-

1 Sobre o financiamento da cafeicultura escravista ver ALMICO, 2001; FRANCO, 1974; MARCONDES, 1998; Idem, 2002 e STEIN, 1961. 
mistas locais no fornecimento de crédito. Em outro trabalho, o autor estudou os empréstimos hipotecários concedidos em Lorena e Guaratinguetá entre 1865 e 1887, tendo percebido que esses prestamistas também dominavam a concessão de empréstimos hipotecários, enquanto que os poucos créditos bancários ali concedidos tinham características muito específicas, pois atendiam a um grupo muito reduzido de grandes fazendeiros da localidade e sob condições de prazo e juros sem paralelo na praça local (Idem: 148).

Tanto a pesquisa de Stanley Stein como a de Renato Marcondes sugeriram que o pequeno interesse do sistema bancário por esse tipo de financiamento estava relacionado à legislação hipotecária vigente. De modo geral, a legislação inviabilizaria a liquidação judicial das propriedades, fazendo com que os credores preferissem a garantia dada em escravos às terras, o que por sua vez implicava num outro problema, pois, na medida em que a libertação dos escravos se tornava evidente no inicio da década de 1880, o crédito hipotecário se contraiu (STEIN, op. cit:: 294-6). Além disso, para Marcondes, a ausência dos bancos no financiamento agrícola também estava relacionada ao fraco desenvolvimento capitalista, e a supremacia do prestamista individual tenderia a ser superada com o avanço das relações capitalistas (MARCONDES, 2002: 148).

Por outro lado, Flávio Azevedo Marques de Saes publicou em 1986 um estudo sobre o desenvolvimento do sistema bancário em São Paulo e apresentou importantes questionamentos a respeito de seu afastamento em relação às operações de crédito com fazendeiros. $\mathrm{O}$ autor demonstrou que os bancos paulistas se desenvolveram rapidamente após 1890, num processo que acompanhou a expansão da cafeicultura; entretanto, eles estavam mais voltados às atividades comerciais e urbanas, sendo que, ao longo de toda a Primeira República, o financiamento agrícola permaneceu como atividade realizada de prestamistas e comissários de café (SAES, 1986: 191). Porém, a introdução do trabalho livre a partir de 1888 somada ao aumento da escala de produção (na década de 1890) e a queda nos preços após 1896 teriam abalado tal sistema, principalmente quando empresas exportadoras passaram a comprar café diretamente no interior.

Desse modo, no final da década de 1890 o sistema de financiamento teria entrado em colapso, levando os fazendeiros a pressionar o Estado no sentido de intervir no financiamento da lavoura (SAES, 1986). Por 
outro lado, Flávio Saes demonstrou ser recorrente a constituição de bancos subsidiados pelo governo para financiar a lavoura, mas que acabavam por concentrar suas atividades no circuito comercial do café ou no meio urbano. Este foi o caso, por exemplo, do Banco de Crédito Real de São Paulo (1882-1906), instituição planejada para fornecer crédito agrícola, mas que atuava na concessão de empréstimos em uma carteira comercial e sobre hipotecas urbanas (SAES, 1986: 66-73).

A descrição feita por Flávio Saes sobre o sistema de crédito demonstra que a constituição de bancos hipotecários não significava necessariamente empréstimos à lavoura, como muitos contemporâneos acreditavam. Colocado esse problema, tornava-se necessário descobrir que mecanismos legais possibilitavam aos bancos criados com a finalidade de financiar a lavoura aplicar seus recursos em empréstimos de caráter comercial e urbano. Nesse sentido, em 2010, Renato Marcondes e Anne Hanley analisaram a repercussão das reformas bancária e hipotecária de 1890 e "desemaranharam" os dispositivos que permitiam a esses bancos agir de tal modo. Eles demonstraram que, ao mesmo tempo em que a nova lei hipotecária avançara no sentido de garantir a liquidação das terras, a reforma bancária permitiu aos bancos hipotecários realizar múltiplas funções de crédito.

As deficiências apontadas em relação ao sistema de crédito não impediram a expansão da cafeicultura paulista no início da Primeira República. Pelo contrário, a transição republicana ocorrera em meio a uma conjuntura muito positiva para a produção de café, de longe o produto mais importante da pauta de exportações do país. Com os preços do café em alta, a sua produção teve uma expansão muito rápida entre o final do Império e início da República. Paralelamente, ocorreu uma transformação na própria produção do café, com a conclusão da substituição do trabalho escravo pelo livre.

A política monetária do primeiro governo republicano e o rápido aumento das exportações de café contribuíram para uma severa depreciação do câmbio, o que permitiu aos fazendeiros venderem seu produto com preço fixado em moeda estrangeira e financiar a produção com a moeda nacional desvalorizada. Celso Furtado chamou esse mecanismo de "socialização dos prejuízos", porque os prejuízos advindos da queda do câmbio eram repassados aos setores não exportadores da sociedade (FURTADO, 2000: 166-169). Ainda que essa não tenha sido 
uma política deliberada em beneficio dos fazendeiros ela contribuiu enormemente para a expansão da cafeicultura. Além disso, com o fluxo de imigrantes para São Paulo assegurado pela imigração subvencionada e com a ampliação da rede ferroviária tal expansão não deixou de se intensificar. As exportações paulistas saltaram de 2,9 milhões de sacas em 1890 e atingiram 6,1 milhões no ano de 1897 (ARAUJO FILHO, 1969: 171-5).

O aumento da produção não tardou a refletir negativamente sobre os preços do produto. Os estoques de café aumentavam nos países compradores e a produção brasileira superava a capacidade de consumo mundial. No início da década de 1890 os preços internacionais já apresentavam uma tendência de queda; porém, devido à depreciação cambial, eles se mantiveram altos em mil-réis, alimentando o ciclo de expansão das plantações e dissimulando a percepção de crise. Todavia, em 1896 os preços passaram a cair em moeda nacional, e os fazendeiros tomaram consciência da crise pela qual a cafeicultura atravessava (Cf. TAUNAY, 1937, v. 10 e DELFIN NETTO, 1981).

Configurava-se, assim, uma situação crítica para a lavoura cafeeira paulista que perdurou de 1896 a 1906. Após 1898, à aguda baixa nos preços somaram-se os efeitos da política de restrição monetária aplicada pelo governo Campos Salles e que visavam impedir a queda do câmbio.Tais medidas inverteram completamente a situação do início da década. Diante desta crise, a condução da política econômica foi alvo de intensos debates na imprensa paulista e no Congresso Legislativo de São Paulo (SAES, 1986).

\section{A reação dos fazendeiros paulistas à crise da cafeicultura}

Nesse momento, fazendeiros paulistas exerciam forte pressão sobre o governo estadual e cobravam a intervenção no sistema de crédito e nos preços do café. Segundo Flávio Saes, embora a crise se devesse muito mais aos desequilíbrios causados pela superprodução, os fazendeiros elegeram a falta de crédito e a especulação baixista dos exportadores como causadora da crise (SAES, 1981:250). A solução apregoada era a criação de um sistema de financiamento que livrasse os fazendeiros da 
dependência em relação ao crédito fornecido por comissários de café e prestamistas locais (Ibidem).

Para Renato Perissinotto (1994), entre 1896 e 1906 a insatisfação de uma parte dos fazendeiros com a política econômica aumentou a ponto de colocar em risco a própria hegemonia local do Partido Republicano Paulista (doravante PRP) ${ }^{2}$. Nesse mesmo sentido, José Ênio Casalecchi afirmara que nunca os paulistas detiveram tanto controle sobre o governo federal como entre 1898 e 1906; porém, até aquele momento o PRP não conhecera tamanha oposição dentro do próprio estado de São Paulo (CASALECCHI, 1987).

Flávio Saes interpretou as disputas em torno da política econômica no período como um embate entre o grande e o médio capital cafeeiro onde, de um lado, encontravam-se indivíduos que, mesmo sendo fazendeiros, possuíam investimentos em companhias, bancos e firmas comerciais, e, de outro lado, aqueles indivíduos que mantinham seus interesses restritos à produção de café. Ambos os grupos possuíam interesses divergentes no tocante à política monetária e cambial e no que se referia ao crédito. $\mathrm{O}$ autor também questionava a ideia recorrente de que o Estado na Primeira República fora simplesmente um espaço de domínio da classe dos fazendeiros de café, visto que a própria classe cafeeira estava cindida em interesses divergentes. Assim, enquanto uma parcela dos fazendeiros cobrava crédito subsidiado e valorização do café eles esbarravam nos interesses de elites político-econômicas de outros estados, interesses de credores internacionais e do próprio grande capital cafeeiro.

Como demonstrou Flávio Saes, ao longo desse período de crise uma parcela dos fazendeiros paulistas mostrava-se profundamente insatisfeita com a condução da política econômica e com a direção do PRP. Nas páginas dos jornais paulistas eles publicavam textos virulentos contra a política monetária e se autodenominavam "a lavoura". Afirmavam que ela era explorada por capitalistas e comissários, atacavam a ganância dos acionistas das estradas de ferro e cobravam a instituição de mecanismo de crédito agrícola. Segundo constatou Casalecchi, "a lavoura” também

2 Sobre a reação dos fazendeiros às políticas econômicas dos governos paulista e federal durante a Primeira República ver PERISSINOTO, 1994: 17-45; SAES, 1986 : 172-180 e TORELLI, 2004. 
não se sentia representada pelos deputados e senadores eleitos pelo PRP e, constantemente, ameaçava a criação de um partido próprio. Em outras ocasiões cobrava a inclusão de seus representantes nas listas de candidatos do PRP. Em 1903 o Partido da Lavoura chegou a publicar um manifesto nas páginas do Correio Paulistano. Para Renato Perissinotto "a lavoura" era a manifestação de uma das frações da classe dominante, representante do médio capital cafeeiro que na esfera econômica estava subordinada ao grande capital cafeeiro e que na esfera política estava subordinada ao grupo que controlava a Comissão Central do PRP. Para Perissinoto, sob constante pressão o Estado tentou dissuadi-los, através de um processo não linear de negociações que incluía a aprovação de leis que contemplavam suas reivindicações, mas que muitas vezes não chegavam a ser cumpridas.

Em seu relatório de 1896 o ministro da Fazenda de Prudente de Morais, Bernardino de Campos, respondia aos reclamos da "lavoura" e confirmava que a falta de crédito era uma das causas daquela crise ${ }^{3}$. Entretanto, o ministro afirmava não ser pertinente a formação de bancos que atuassem exclusivamente com o crédito agrícola, principalmente quando auxiliados pelo Estado. Seu sucessor no ministério, Joaquim Murtinho, tinha opinião um tanto diferente a respeito da crise. Em seu primeiro relatório ele acusava a abundância de crédito no inicio da década como responsável pela expansão descontrolada que causara a superprodução.

Murtinho interpretava a crise como estrutural, e não como uma desordem momentânea, tal como acreditava seu antecessor. Ele estava convicto de que o excesso de crédito causara uma anomalia no sistema produtivo, ao permitir que os fazendeiros "mais débeis" obtivessem condições artificiais de sobrevivência frente aos "mais fortes" no processo de seleção natural ${ }^{4}$. Para Murtinho, o crédito deveria ser estancado, tanto para sanear a moeda como para eliminar os produtores marginais.

3 BRASIL. Ministério da Fazenda. Relatório apresentado ao Presidente da Republica dos Estados Unidos do Brazil pelo Ministro de Negocios da Fazenda Bernardino de Campos, No anno de 1897 [Referente ao ano de 1896]. Rio de Janeiro: Imprensa Nacional, 1897: 180.

4 BRASIL. Ministério da fazenda. Relatorio apresentado ao Presidente da Republica dos Estados Unidos do Brasil pelo Ministro de Estado dos Negocios da Fazenda Joaquim Murtiho, no anno de 1899. Rio de Janeiro, Imprensa Nacional, 1899. 
Bernardino de Campo adotara um tom contemporizador entre os interesses favoráveis e contrários ao socorro da lavoura, enquanto Joaquim Murtinho emitia opiniões que causaram consternação em grande parte dos fazendeiros paulistas. Ele refutava veementemente as propostas de intervenção no mercado de café e afirmava que a verdadeira valorização viria como "resultado da luta, da concorrência entre os diversos lavradores, produzindo por meio de liquidações e seleção natural, manifestada pelo desaparecimento dos inferiores e pela permanência dos superiores" ${ }^{5}$. Era o próprio mercado, através da concorrência, quem deveria se encarregar de solucionar o problema da crise, eliminando os fazendeiros endividados e aqueles que exploravam terras de produtividade inferior, salvando-se apenas os proprietários mais austeros, que aprimoraram os métodos de cultivos e que exploravam terras superiores.

\section{O crédito associativo como solução para o problema do financiamento}

No relatório de 1896, o ministro Bernardino de Campos havia refutado qualquer possibilidade de o Estado vir a subsidiar bancos agrícolas; no entanto, ele propôs a adoção de um modelo de financiamento "paralelo" ao mercado de crédito e independente do Estado. A sua proposta era a formação de cooperativas de crédito que captariam os depósitos no interior do estado e, uma vez munidos dessa poupança e de empréstimos levantados junto à rede bancária, concederiam empréstimos aos fazendeiros associados. Tal proposta não negava o argumento da lavoura contra o sistema de crédito, mas escapava aos esquemas emissionistas propostos até então.

No mesmo relatório, o ministro discorreu longamente sobre o crédito agrícola na Europa e demonstrou que, exceto na Inglaterra e na Escócia, os bancos tradicionais também não emprestavam à lavoura, e os produtores recorriam a organização de bancos populares e caixas rurais, como as caixas Raiffeisen (Alemanha) e os bancos Luzatti (Itália) ${ }^{6}$.

Idem, Ibidem.: XXIV.

6 BRASIL, Ministério da Fazenda. Relatório apresentado [...] pelo Ministro de Negocios da Fazenda Bernardino de Campos, No anno de 1897. Rio de Janeiro: Imp. Nacional, 1897: 180-210. 
O ministro pretendia que esse modelo fosse reproduzido no Brasil, com as redes de cooperativas ligando pequenos e grandes produtores ao sistema bancário.

$\mathrm{Na}$ Europa, o cooperativismo fora concebido a partir de inúmeras vertentes doutrinárias antiliberais, principalmente cristãs e socialistas, e tinham como objetivo formar poupanças, socorrer operários e financiar artesãos e camponeses. No entanto, as cooperativas voltadas ao crédito rural adquiriram grande importância econômica e, em finais do século XIX, os socialistas de tendência marxista acusavam-nas de lubrificarem as engrenagens do sistema capitalista. Elas seriam responsáveis por grande parte do financiamento agrícola e possibilitavam ao pequeno camponês o acesso ao mercado de crédito (Cf. KAUTSKY, 1986: 108-118).

No Brasil, o associativismo surgia como uma proposta de governo, apoiada por associações de grandes fazendeiros, como a Sociedade Brasileira de Agricultura. Assim, enquanto os partidários da "lavoura" cobravam a criação de bancos agrícolas que emitissem bilhetes hipotecários e até mesmo empréstimos concedidos pelo tesouro, o governo federal lhes propunha a organizarem-se em cooperativas para provisão dos recursos demandados para o financiamento. Essa era uma forma de tentar regularizar o credito agrícola sem onerar o tesouro com auxílios, subvenções e autorização de emissão para bancos agrícolas que, muitas vezes, desviavam-se de seus propósitos. Portanto, a proposta do crédito associativo surge em conformidade com as balizas liberais da austeridade fiscal e valorização do mil-réis.

O primeiro regulamento sobre o assunto surgiu em janeiro de 1903 com o decreto legislativo número 979, uma lei restrita ao âmbito agrário que autorizava "aos profissionaes da agricultura e industrias ruraes de qualquer genero organisarem entre si syndicatos para o estudo, custeio e defesa dos seus interesses", sendo-lhes permitido a "organisação de caixas ruraes de credito agricola e de cooperativa de producção ou de consumo, de sociedade de seguros, assistência, etc" tivo dessa lei era criar uma nova figura jurídica cuja formação fosse menos onerosa do que as sociedades e companhias regulamentadas pela lei das sociedades anônimas.

7 BRASIL."Portal de Legislação." Senado Federal. 6 de Janeiro de 1903.< http://www6. senado.gov.br/legislacao/ListaPublicacoes.action?id=58693\&tipoDocumento=DE C\&tipoTexto=PUB (acesso em 6 de Março de 2012)>. 
A ação do governo federal, nesse sentido, também se refletia nos governos dos estados de São Paulo e Minas Gerais. Em Maio de 1903 foi realizado o Congresso agrícola, comercial e industrial em Minas Gerais, organizado por João Pinheiro durante a presidência de Francisco Salles. O congresso tinha por objetivo debater e propor soluções para o combate à crise econômica, onde foi discutida a criação de caixas cooperativas do tipo Raiffeisen ${ }^{8}$. Mais tarde, em 1907, quando ocupava a presidência do estado, Pinheiro incentivou a organização das primeiras cooperativas de café em Minas Gerais (Cf. SOARES, 1914).Também no ano de 1903 Bernardino de Campos ocupava a presidência de São Paulo e convocou uma sessão extraordinária do Congresso Legislativo para discutir as medidas necessárias para o combate à crise da lavoura. Em seu relatório ele explicava que:

Attendendo ás representaçoes de uma delegação de lavradores, o Governo convocou o Congresso para uma sessão extraordinária que se abriu em 5 de Março de 1903 para tomar conhecimento dos assumptos concernentes á lavoura e resolver como julgasse acertado quanto ao seu provimento'.

Anteriormente, o Congresso havia nomeado uma comissão incumbida de propor medidas destinadas a minorar os efeitos da crise da lavoura de café. Essa comissão realizou uma enquete, ouviu as Câmaras Municipais do interior e apresentou como resultado um projeto que fora discutido nesta sessão e transformado na lei n. 866 na sessão extraordinária de sete de abril.

Entre as medidas estabelecidas pela nova lei estavam: a criação de uma sobretaxa sobre os cafés de menor qualidade (que exerciam pressão baixista sobre os preços); autorização para que o governo entrasse em acordo com os demais estados para promover a valorização do café; "auxiliar a fundação de syndicatos e cooperativas agricolas que se organizem sobre bases approvadas pelo Governo"; e a subscrição de até 50\% das ações

8 FUNDAÇÃO JOÃO PINHEIRO, "Congresso agrícola, comercial e industrial de Minas Gerais, em 1903”. Análise e Conjuntura, Belo Horizonte, v. 11, n. 5: 122-220, Mai-Jun 1981 n. 3.

9 SÃO PAUlO. Mensagem enviada ao Congresso Legislativo a 7 de Abril de 1904 pelo Dr. Bernardino de Campos, Presidente do Estado. São Paulo:Typ. Diario Official, 1904: 21. 
de um banco de crédito agrícola a ser criado. Paralelamente, era previsto um socorro à lavoura no valor de 25.000:00 $\$ 000$, o qual seria fornecido através do futuro banco agrícola e das cooperativas que se formas$\mathrm{sem}^{10}$. Um ano depois, Bernardino de Campos buscava responder por que apenas o imposto sobre os cafés baixos fora aplicado e por que, ao invés de aplicar as medidas previstas de incentivo ao crédito agrícola, ele socorreu duas vezes seguidas o Banco de Crédito Real ${ }^{11}$.

Entre 1899 e 1904 acumulavam-se leis aprovadas com o objetivo de melhorar as condições de crédito e intervir no mercado de café. No entanto, essas leis não chegavam a ser aplicadas. A maioria delas, entretanto, foi aplicada ou reeditada quando a crise se intensificou, em 1906, como é o caso do próprio convênio de Taubaté, previsto desde a aprovação da lei 866, mas que de fato só foi encampado pelo governo paulista em 1905, quando a previsão de uma safra recorde derrubou os obstáculos à intervenção governamental e praticamente todas as medidas autorizadas pela lei 866 começaram a ser executadas.

Em 1904, Bernardino de Campos foi sucedido por Jorge Tibiriçá, que assumiu a presidência do estado com o objetivo de restabelecer a unidade política abalada pela crise. Desde 1896 o partido tentava abafar as tentativas de criação do Partido da Lavoura. Em 1901, surgira a dissidência do Partido Republicano Conservador, liderada por Prudente de Moraes e Julio de Mesquita e, em 1902, surgia o Partido Monarquista. As lutas no interior do bloco de poder atingiam o seu ápice entre 1903 e 1905. Em certo momento, os três principais jornais de São Paulo passaram para a oposição: O Estado de São Paulo aderiu ao Partido Republicano Conservador, O Commercio de São Paulo rompeu junto com os monarquistas e até mesmo o Correio Paulistano, órgão oficial do partido, passou a defender a criação do Partido da Lavoura (Cf. CASALECCHI, 1987).

A crise era tão séria que Bernardino de Campos, ao transferir o cargo a seu sucessor, fazia-lhe o seguinte alerta: "Jorge, você vai governar com um espinho atravessado na garganta - a dissidência" (CASALECCHI, op. cit.: 124-5). Entretanto, Tibiriçá pôs em prática uma políti-

10 SÃO PAULO. "Legislação Do Estado De São Paulo." ALESP. <http://www.al.sp. gov.br/repositorio/legislacao/lei/1903/lei\%20n.866,\%20de\%2007.04.1903.htm> (acesso em 12 de Março de 2012).

11 SÃO PAUlO. Mensagem [...] 7 de Abril de 1904 [...] Bernardino de Campos, Presidente do Estado. São Paulo:Typ. Diario Official, 1904: 27-8. 
ca de negociações com os dissidentes e escolheu alguns de seus membros para as secretarias. Em seu programa de governo ele havia incluído várias das reivindicações oposicionistas e, depois de eleito, pôs em prática o chamado "congraçamento", processo de reorganização do PRP e assimilação das dissidências, concluído no congresso do partido em setembro de 1906 (Idem: 126).

Foi no governo de Jorge Tibiriçá que as medidas aprovadas em 1903 começaram a ser aplicadas, de modo que em agosto de 1904 foi aprovada a lei n. 923, que viabilizava o banco agrícola, prevista na lei 866 de 1903 e, no ano seguinte, o governo paulista entrou em negociação com um consórcio de capitalistas franceses que resultou na assinatura de um contrato para organização do Banco de Crédito Hipotecário e Agrícola do Estado de São Paulo, que começou a operar em 1909². Em 1906, foi aprovada a lei estadual n. 1.062, que provisionava um auxílio às cooperativas de crédito chamadas Bancos de Custeio Rural, cujo projeto de lei tramitava no Congresso desde 1903 e que também estavam previstas na lei 866. Esses bancos entraram em funcionamento em 1907 e se espalharam rapidamente pelo interior paulista.

\section{Os Bancos de Custeio Rural}

Em 29 de Dezembro de 1906 era aprovada a lei estadual n. 1.062, que destinava um auxílio às cooperativas de crédito chamadas Bancos de Custeio Rural (BCR). Essa lei estabelecia as exigências estatutárias mínimas e as condições para que tais bancos pudessem receber um empréstimo de 500 contos de réis em apólices do tesouro. Receberiam este auxílio os primeiros dez bancos que fossem organizados por uma entidade chamada Sociedade Incorporadora. Para dar lastro às atividades desses bancos, criou-se uma nova modalidade de título mobiliário, a Apólice de Auxilio Agrícola. Essas apólices deveriam ser utilizadas para garantir os empréstimos que as cooperativas levantariam junto ao sistema bancário. Este auxílio não deveria ser permanente, visto que os

12 SÃO PAULO. Relatorio Apresentado ao Dr. Jorge Tibiriçá, Presidente do Estado, Pelo Dr. Olavo Egydio de Souza Aranha, Secretario da Fazenda, 1907. São Paulo:Typ. do Diario Official, 1908. 
bancos deveriam arrecadar fundos através de depósitos e junto ao sistema bancário ${ }^{13}$.

Os Bancos de Custeio só podiam emprestar aos fazendeiros associados o valor que fosse estritamente necessário ao custeio anual da produção e mediante a garantia do penhor da safra. Eles deveriam cumprir uma função bastante específica dentro do sistema de crédito, que era a manutenção do fluxo de caixa das fazendas, papel que normalmente coubera aos comissários de café.

Já a Sociedade Incorporadora fora criada em agosto de 1906 para organizar os Bancos de Custeio. Ela deveria centralizar suas operações e os ativos financeiros, além de contrair empréstimos junto à rede bancária, redistribuindo-os aos bancos associados. Formava-se assim uma rede de cooperativas que também deveria realizar transferências de dinheiro entre cidades e descontos de cheques emitidos por associados ${ }^{14}$.

Havia um elevado número de reclamações por parte da lavoura contra comissários e capitalistas, acusados de abandonar os fazendeiros em detrimento da "especulação" e do financiamento do comércio. Por conta disso, os Bancos de Custeio Rural foram blindados contra operações tidas como especulativas. Eles só podiam emprestar aos fazendeiros associados e à Sociedade Incorporadora que, por sua vez, só podia conceder crédito aos bancos associados ${ }^{15}$. Além disso, apesar de se constituírem como sociedades anônimas, os Bancos de Custeio deveriam atuar como cooperativas. O poder de cada acionista era limitado a um voto, independente do número de ações que ele possuísse; as ações só podiam ser negociadas entre os sócios e os dividendos estavam limitados em $6 \%$ ao ano. Assim, eliminava-se o risco de que uma parcela dos acionistas concentrasse o poder da sociedade e, ao mesmo tempo, impedia-se o uso especulativo das ações, pois o número de ações adquiridas apenas determinava o valor dos empréstimos. Desse modo, as ações não funcionavam como partícula de propriedade, mas como uma espécie de cota de participação num bem cuja gestão era coletiva.

\footnotetext{
13 Lei 1.062 , de 29 de Dezembro de 1906.

$141^{\circ}$ REGISTRO DE IMÓVEIS DA CAPITAL. SOCIEDADE INCORPORADORA. Estatutos da Sociedade Incorporadora.

15

Idem.
} 
Em 1907, o governo estadual aprovou os estatutos e firmou contratos para auxiliar Bancos de Custeio Rural em Jaboticabal, Ribeirão Preto, Ribeirão Bonito, Serra Negra, Sertãozinho, Jaú e Taubaté, que receberam 50 contos de reis em apólices de auxilio agrícola ${ }^{16}$. Além desses sete bancos estavam organizados os Bancos de Custeio Rural de Avaré, Bragança, Botucatu, Itapira, Pindamonhangaba e São José do Rio Pardo. Em Novembro de 1907, o senador Antônio Cândido Rodrigues apresentou um projeto de lei propondo aumentar em 500 contos de réis a emissão de apólices ${ }^{17}$, e em Dezembro de 1907 foi aprovada a lei n.1.112, que elevou para vinte o número de bancos auxiliados.

No início de 1908 foram aprovados os estatutos dos BCR de Botucatu, Pindamonhangaba e São José do Rio Pardo. Em junho, quando uma comissão de fiscalização da Secretaria da Fazenda visitou tais bancos, constatou-se que eles estavam operando normalmente ${ }^{18}$. No segundo semestre foram autorizados auxílios aos bancos de Descalvado, Jacareí, Lorena, Limeira, Santa Cruz do Rio Pardo, Pirassununga e Itapira ${ }^{19}$ e, em 1909, foram aprovados os estatutos de bancos em Taquaritinga, São Manoel e Santa Rita do Passa Quatro ${ }^{20}$. Esses vinte primeiros bancos foram beneficiados pelo auxílio em apólices e estavam submetidos à fiscalização da Secretaria da Fazenda ${ }^{21}$.

Até 1913 surgiram quarenta e oito Bancos de Custeio associados à Incorporadora, sendo que vinte e oito não receberam auxílios. Entre estes estava o de Campinas que, embora tenha sido organizado em 1908, não obteve apólices. No Anuário Estatístico de 1909 aparecem os BCR

16 SÃO PAULO. Mensagem enviada ao Congresso Legislativo do Estado a 14 de Julho de 1908 pelo Dr. M. J; Albuquerque Lins, Presidente do Estado.

17 Correio Paulistano, 8/11/1907, pp. 1-2 - "O Sr. Candido Rodrigues".

18 SÃO PAULO. Relatorio [...] Secretario da Fazenda, 1907. São Paulo: Typ. do Diario Official, 1908. Diario Official do Estado de São Paulo, 12/5/1907, p. 1445 - "Acta da assembleia extraordinaria do Banco de Custeio Rural de Ribeirão Bonito, em 14 de Abril de 1907".

19 SÃO PAULO. Secretaria de Fazenda e do Thesouro do Estado de S. Paulo, Directoria de Fiscalização. Indice de Leis e Decretos da Secretaria da Fazenda de 1889 a 1933. São Paulo: Typ. Bancaria, 1934.

20 SÃO PAULO. Congresso Legislativo do Estado de São Paulo. Coleção de leis e decretos do Estado de São Paulo. São Paulo: Imprensa Oficial do Estado, 1933.

21 SÃO PAULO. Relatorio Apresentado ao Dr. Manuel Joaquim de Albuquerque Lins, Presidente do Estado, Pelo Dr. Carlos Augusto Pereira Guimarães, Secretario Interino da Fazenda, 1910. São Paulo:Typ. Casa Garraux, 1911. 
de Caçapava, Caconde, Casa Branca, Rio Claro e São Simão (vinte e seis bancos). No ano de 1910 surgiram os bancos nas localidades de Agudos, Bauru, Itatinga, Piracaia e São Carlos (trinta e um). Em 1911 aparecem os bancos de Araraquara, Franca, Ibitinga, Mococa, Palmeiras e Piracicaba (trinta e seis). Em 1912 surgem os BCR de Bebedouro, Dois Córregos, Dourado, Igarapava, Itápolis, Monte Alto, Orlândia, São João da BoaVista e Salto Grande do Paranapanema (quarenta e cinco) ${ }^{22}$. Em 1914, de acordo com o relatório de falência da Sociedade Incorporadora, havia Bancos de Custeio em Amparo, Espírito Santo do Pinhal e São José do Rio Preto (quarenta e oito).

Localização dos Bancos de Custeio em 1913

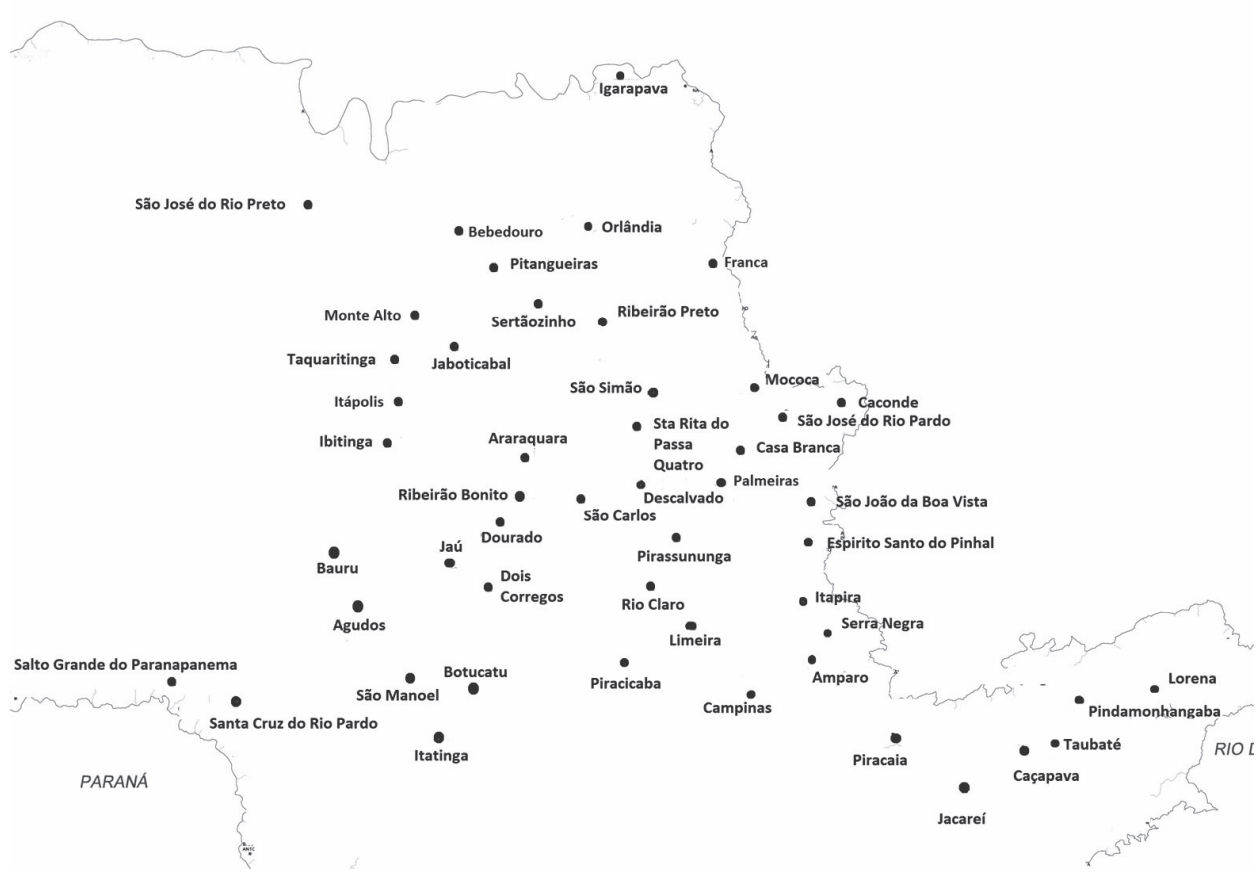

22 SÃO PAULO. Repartição de Estatística e Arquivo do Estado. Annuario Estatístico de São Paulo, 1911. Estatísticas Econômicas e Financeiras.Vol. II, São Paulo:Typ. Brazil de Rothschild, 1913. 
Em 1903, foram criados três BCR: um em Capivari, organizado por Jacintho de Barros, mas que encerrou suas atividades no mesmo ano; o de Ribeirão Bonito, reorganizado em 1907 para se associar à Incorporadora e existente até 1914; e o de Avaré, organizado por Antônio Cândido Rodrigues, mas que não constatamos seu funcionamento após $1907^{23}$. Em Bragança chegou a ser organizado um Banco de Custeio em $1907^{24}$, mas não foi possível averiguar sua continuidade. No Anuário Estatístico de 1912 apareceu também o Banco de Custeio Rural de Pitangueiras, que não figurava na relação de bancos associados à Incorporadora, mas que vinha emprestando regularmente. Desse modo, o número confirmado de Bancos de Custeio existentes em 1913 era de 49 , sendo 48 organizados pela Incorporadora, dos quais vinte eram auxiliadas pelo governo.

\section{Forma de captação de recursos e concessão do financiamento}

A operação de crédito realizada pelos Bancos de Custeio Rural consistia em um contrato de penhor estabelecido junto ao fazendeiro acionista que lhe garantia o financiamento por três anos e cobria o custeio de três safras consecutivas. O valor do empréstimo era estipulado com base numa estimativa do custo anual de produção da fazenda. Nesse contrato, enquanto o banco se comprometia a conceder os empréstimos, o fazendeiro deveria emitir no início de cada ano uma letra de câmbio em favor do banco, com vencimento para doze meses.

O banco recebia a letra de câmbio do fazendeiro e realizava o desconto; no entanto, ele não entregava o seu valor imediatamente ao fazendeiro, dividindo-o em doze parcelas que eram creditadas mensalmente em sua conta corrente.

A liquidação do empréstimo se fazia pelo pagamento da letra mais uma taxa de $6 \%$, que era considerada a taxa de juro anual do financiamento. Em seguida, dando continuidade ao contrato, o fazendeiro

23 Correio Paulistano, 8/11/1907: 1-2 - "O Sr. Candido Rodrigues".

24 Correio Paulistano, 29/11/1906: 3 - "Bragança". 
emitia uma nova letra para o próximo período e a operação se repetia por mais duas vezes até o fim do contrato ${ }^{25}$.

Tomemos como exemplo o contrato estabelecido entre o Banco de Custeio Rural de Campinas e o fazendeiro Joaquim Antonio Leite de Oliveira, inscrito no registro de hipotecas daquela comarca em 15 de janeiro de 1912. Este contrato tinha vigência de três anos e estabelecia um financiamento de 10 contos de réis por ano e taxa de desconto de $6 \%$. Nessa operação o fazendeiro emitiu, em favor do banco, uma letra de câmbio no valor 10 contos de réis, a qual o banco descontou e colocou-lhe à disposição 833,333 mil-réis mensalmente em uma conta corrente. Tal operação estava garantida pelo penhor de seis mil arrobas de café, duas mil de cada uma das safras de 1912, 1913 e $1914^{26}$.

Além dessa relação entre fazendeiros e Banco de Custeio Rural, havia um segundo circuito de operações que se estabelecia entre os Bancos de Custeio e a Sociedade Incorporadora e desta com os bancos da capital. Nesse circuito, as letras de câmbio garantidas pelos contratos de penhor eram repassadas à Incorporadora, que as utilizava como caução de empréstimos tomados junto a bancos como o London and Brazilian Bank, Britsh Bank, Banque Brésilienne Italo-Belge, Caixa Filial do Banco do Brasil e o Banco de Crédito Hipotecário e Agrícola do Estado de São Paulo ${ }^{27}$, recursos tais que posteriormente eram repassados aos BCR. De acordo com os embargos realizados pelos credores durante a falência da Incorporadora em 1914 constatou-se que esses recursos foram captados com taxas que variaram entre $8 \%$ e $12 \%$.

O quadro abaixo demonstra as operações de crédito realizadas pelos Bancos de Custeio Rural em 1910:

25 Diario Official do Estado de São Paulo. 1/2/1907 "Estatutos do Banco de Custeio Rural de Jaboticabal"

26 SÃO PAULO.TJSP:ARQUIVO GERAL. " $2^{\circ}$ oficial da $1^{a}$ Vara Commercial de São Paulo", Processo de Fallencia, Sociedade Incorporadora (v. 1), n. 12.504, cx 431: 111-114 (Contrato de penhor anexado ao processo).

27 SÃO PAULO.TJSP:ARQUIVO GERAL. " $2^{\circ}$ Oficial da $1^{a}$ Vara Commercial de São Paulo", Processo de Fallencia, Sociedade Incorporadora (v. 2), n. 12.659 cx 431: 420-437. 


\begin{tabular}{|c|c|c|c|c|}
\hline \multicolumn{5}{|c|}{ Quadro 1 - Operações de crédito realizadas pelos BCR em 1910 (réis) } \\
\hline Banco de Custeio & $\begin{array}{l}\text { Valor dos } \\
\text { contratos }\end{array}$ & $\begin{array}{l}\text { Valor das } \\
\text { parcelas }\end{array}$ & $\begin{array}{l}\text { Recursos } \\
\text { levantados }\end{array}$ & $\begin{array}{l}\text { Saldo junto a } \\
\text { Incorporadora }\end{array}$ \\
\hline Botucatu & 130.200 & 10.850 & 108.450 & -68.719 \\
\hline Descalvado & 332.500 & 27.708 & 333.500 & 112.329 \\
\hline Itapira & 247.389 & 20.616 & 210.394 & 202.198 \\
\hline Jaboticabal & 265.500 & 22.125 & 172.000 & 191.715 \\
\hline Jacareí & 130.849 & 10.904 & 136.545 & 73.629 \\
\hline Jau & 361.700 & 30.142 & 307.200 & 2.035 \\
\hline Limeira & 130.300 & 10.858 & 130.300 & 109.125 \\
\hline Lorena & 147.684 & 12.307 & 147.684 & -2.759 \\
\hline Pindamonhangaba & 155.500 & 12.958 & 179.600 & -64.098 \\
\hline Pirassununga & 77.400 & 6.450 & 54.600 & 12.850 \\
\hline Ribeirão Bonito & 168.800 & 14.067 & 136.700 & 69.951 \\
\hline Ribeirão Preto & 530.300 & 44.192 & 440.300 & -142.643 \\
\hline Santa Cruz & 39.500 & 3.292 & 39.500 & -183 \\
\hline Santa Rita & 146.000 & 12.167 & 143.000 & 30.058 \\
\hline S. J. do Rio Pardo & 351.600 & 29.300 & 309.600 & 281.854 \\
\hline São Manoel & 66.500 & 5.542 & 66.500 & 53.198 \\
\hline Serra Negra & 96.220 & 8.018 & 96.220 & 25.000 \\
\hline Sertãozinho & 302.000 & 25.167 & 317.000 & 68.986 \\
\hline Taquaritinga & 238.800 & 19.900 & 185.800 & -86.664 \\
\hline Taubaté & 126.400 & 10.533 & 171.630 & 57.799 \\
\hline Total & 4.045 .142 & 337.095 & 3.686 .523 & 925.662 \\
\hline
\end{tabular}

Os vinte bancos fiscalizados pela Secretaria da Fazenda haviam realizado contratos de penhor no valor de 4.045:142\$000 e pagavam aos seus mutuários parcelas mensais num total de 337:095\$000. Para realizar esses empréstimos fora contraído junto aos bancos da capital 3.686:523\$000. Deste montante, 925:662\$000 estavam em poder da Sociedade Incorporadora ${ }^{28}$.

28 SÃO PAUlO. Relatorio [...], Secretario da Fazenda, 1907. São Paulo: Typ. do Diario Official, 1908. 


\section{A falência da Sociedade Incorporadora}

Em 1914, a Sociedade Incorporadora faliu abruptamente. O processo de falência revelou operações ilegais de desconto de letras emitidas por casas comerciais, muitas das quais quebraram durante a crise financeira no final de 1913. Num desses casos a Incorporadora havia descontado letras emitidas pela casa comissária Uchoa \& Cintra, que foram endossadas (afiançadas) e redescontadas na Caixa Filial do Banco do Brasil. Como esta casa quebrou e não liquidou suas letras no vencimento, a Caixa filial protestou a dívida. Os endossos tornaram a Incorporadora corresponsável pelos pagamentos, e ela teve de pedir falência no dia 2 de Janeiro de 1914.

Nos cinco bancos citados anteriormente a Incorporadora havia realizado o mesmo tipo de operação. Ela solicitava um empréstimo em conta corrente e, ao mesmo tempo, redescontava títulos de terceiros por ela endossados. Essas operações eram, por sua vez, garantidas pelas letras de câmbio dos fazendeiros e apólices pertencentes aos Bancos de Custeio. Numa dessas operações, junto ao The Britsh Bank of South America, ela redescontou letras num total de 300:200\$000 e contratou um empréstimo em conta corrente no valor de 277:939\$820 à taxa de 11\% ao ano. Como garantia desta operação ela entregou ao banco 623:100\$000 em títulos de penhor e 300:000\$000 em apólices do auxilio agrícola ${ }^{29}$.

Tendo analisado como os Bancos de Custeio realizavam os empréstimos aos fazendeiros e como eles levantavam esses recursos junto à rede bancária, falta ainda discutir como tal sistema poderia funcionar se os empréstimos fossem concedidos à taxa de $6 \%$ ao ano, enquanto os recursos eram captados a uma taxa que variava entre $8 \%$ e $12 \%$.

Em primeiro lugar, a taxa de juros cobrada pelos BCR não era efetivamente de $6 \%$ ao ano. Esses bancos faziam o desconto da letra dos fazendeiros a uma taxa de $6 \%$, mas, como o dinheiro era entregue em parcelas mensais e eles seguravam consigo o restante, a taxa real de juros era maior.

Em segundo lugar, a Incorporadora pôs em operação um mecanismo de desconto e redesconto de títulos comerciais que se explica da se-

29 SÃO PAULO.TJSP:ARQUIVO GERAL. " $2^{\circ}$ Oficial da $1^{\mathrm{a}}$ Vara Commercial de São Paulo", Processo de Fallencia, Sociedade Incorporadora (v. 2), n. 12.659 cx 431: 423. 
guinte maneira:uma parte dos recursos captados era remetida aos BCR para o pagamento das parcelas devidas aos fazendeiros e o restante permanecia no caixa da Incorporadora. Assim, entre a captação dos recursos e a sua total remetida aos Bancos de Custeio havia um intervalo no qual a Incorporadora aplicava esse dinheiro em desconto de letras de curto prazo, geralmente com taxas maiores.

O resultado da operação com títulos comerciais compensava a diferença entre a taxa de juro paga na captação e a taxa cobrada para custeio agrícola que, na realidade, era superior a $6 \%$. Essas operações foram descritas no relatório do processo de falência da Sociedade Incorporadora.

O quadro a seguir demonstra as operações que a Sociedade Incorporadora realizava com terceiros e que montavam a 2.673:845 $\$ 594$, entre contas correntes e descontos.

\begin{tabular}{|l|c|}
\hline Quadro 2 - Relações da Sociedade Incorporadora com terceiros \\
\hline Títulos descontados de terceiros (em carteira e caucionados) & $1.945: 951 \$ 030$ \\
\hline Contas correntes abertas a terceiros & $727: 894 \$ 564$ \\
\hline Total do crédito concedido a terceiros & $2.673: 845 \$ 594$ \\
\hline $\begin{array}{l}\text { Fonte: SÃO PAULO. TJSP: ARQUIVO GERAL. “2 } 2^{\circ} \text { oficial da 1ª Vara Commercial de São Paulo”, } \\
\text { Processo de Fallencia, Sociedade Incorporadora (v. 1), n. } 12.504, \text { cx 431: 250-260. }\end{array}$ \\
\hline
\end{tabular}

Os síndicos da massa falida produziram uma lista dos títulos de terceiros em poder da companhia na qual foi possível observar que a taxa de desconto variou entre $10 \%$ e $12 \%$; porém, não havia indicação de prazo e nem como os havia adquirido ${ }^{30}$. A respeito dos empréstimos em conta corrente os síndicos afirmaram que eles foram concedidos a comerciantes, muitas vezes sem garantia.

Os Bancos de Custeio Rural chegaram a emprestar 11 mil contos de réis a fazendeiros no ano de 1912, uma quantia admirável visto se tratar de $8 \%$ dos empréstimos concedidos pelos bancos nacionais naquele ano (SAES, 1986: 222). Entretanto, em que pese o seu rápido desenvolvimento, eles desapareceram logo após a falência da Sociedade Incorporadora.

30 Idem, lista de descontos sem indicação de página. 


\section{Conclusão}

A constituição dos Bancos de Custeio Rural é fruto de um intenso debate que ocorreu ao longo da crise de 1896-1906 em que se discutia uma forma de instituição que regularizasse o financiamento agrícola e livrasse os fazendeiros da intermediação financeira dos comissários de café. Assim, buscamos compreender a criação dos Bancos de Custeio dentro de um processo mais amplo de disputa em torno das políticas econômicas adotadas pelo governo estadual e federal no início da Primeira República.

A crítica que os fazendeiros faziam ao sistema de crédito era a de que os bancos preferiam o investimento em atividades não agrícolas, fosse através da compra de títulos e ações, fosse pelo desconto de letras ou empréstimos a comerciantes e "capitalistas". Outro problema apontado é o de que o crédito desaparecia nos momentos de crise, obrigando os fazendeiros a vender seu produto com deságio em troca de adiantamentos.

Assim, surgem vários projetos para a criação de bancos que fossem apartados das atividades não agrícolas e que mantivessem a regularidade do financiamento. Para os fazendeiros, isso se traduzia na criação de um banco hipotecário garantido e fiscalizado pelo Estado. No entanto, as tentativas de auxílio a esse tipo de banco em São Paulo foram onerosas e não surtiram o efeito esperado. Assim, em 1896 o ministro Bernardino de Campos sugeria que se adotasse a prática do cooperativismo de crédito como forma de estabelecer o crédito agrícola sem onerar os cofres públicos.

O objetivo dos Bancos de Custeio era prover a lavoura de um meio de financiamento constante e, ao mesmo tempo, independente das especulações no mercado de crédito. Porém, a falência da Sociedade Incorporadora demonstrou como o sistema de crédito era determinado por operações de curto prazo e alto risco. A própria Sociedade Incorporadora estava envolvida nesse tipo de atividade que não era apenas acessória, pois que sustentava as operações com o penhor agrícola. Por outro lado, o período de funcionamento dos Bancos de Custeio foi de grande estabilidade nos preços do café, proporcionada pela valorização. No entanto, eles faliram na primeira crise financeira que enfrentaram justo no momento em que mais se poderiam fazer necessários. 


\section{Referências bibliograficas}

ALBUQUERQUE, Diogo Velho C. de. Regimen Hypothecario. s/n, 1918.

ALMICO, Rita de C. Dívida e obrigação: as relações de crédito em Minas Gerais, séculos XIX/XX. Niteroi: UFF (Tese de doutorado), 2009.

ARAUJO FILHO, José Ribeiro de. Santos, o Porto do Café. Rio de Janeiro: IBGE, 1969

BARROS, Jacintto. Credito Agropecuario. São Paulo: Salesiano, 1917.

CASALECCHI, José Ê. O Partido Republicano Paulista (1889-1926). São Paulo-SP : Editora Brasiliense, 1987.

CARONE, E. A República velha. São Paulo: Difel, 1972 (1ª ed. 1970), v.2.

CANO, W. Raízes da Concentração Industrial de S. Paulo. São Paulo: Queiroz, 1981.

DEAN, Warren. Rio Claro: um sistema brasileiro de grande lavoura, 1820-1920. Rio de Janeiro: Paz e Terra, 1977.

DELFIM NETTO, Antonio. O problema do café no Brasil. São Paulo: IPE/USP, 1981.

FALEIROS, Rogério N. Fronteiras do Café: Fazendeiros e Colonos no Interior Paulista (1917-1937). Bauru: Edusc, 2010.

FRANCO, Antonio de L. Estudos sobre a Aplicação da mutualidade ao credito rural e agrícola no Brasil. São Paulo: Ed. Spindola, 1900.

FRANCO, Maria Sylvia de C. Homens livres na ordem escravocrata. São Paulo: Ática, 1974.

FONTANARI, Rodrigo. O problema do financiamento: uma análise histórica sobre o crédito no complexo cafeeiro paulista. Casa Branca (1874-1914). Franca: Unesp (Dissertação de Mestrado), 2001.

FURTADO, Celso. Formação Econômica do Brasil. São Paulo: Cia. Ed. Nacional/Publifolha, 2000.

GAMA, Affonso D. Penhor: civil, mercantil e agricola. Sao Paulo: Saraiva, 1919.

HANLEY,Anne G. e MARCONDES, Renato L. "Bancos na transição republicana em São Paulo: o financiamento hipotecário (1888-1901)". Estudos Econômicos, São Paulo, v. 40, n. 1: 103-131 JANEIRO-MARÇO 2010.

HOLLOWAY,T. Vida e Morte do Convenio de Taubaté. Rio de Janeiro: Paz e Terra, 1978.

KAUTSKY, Karl. A questão agrária. São Paulo: Nova Cultural, 1986.

KUGELMAS, Eduardo. A Difícil Hegemonia: Um Estudo Sobre São Paulo na Primeira República. São Paulo: FFLCH-USP (Tese do doutorado), 1987.

LEAL, Victor Nunes. Coronelismo Enxada e Voto (O município e o Regime Representativo no Brasil). São Paulo: Alfa-Omega, 1978.

MARCONDES, Renato L. A arte de Acumular na economia cafeeira: Vale do paraíba século XIX. Lorena: Stiliano, 1998.

.'O financiamento hipotecário da cafeicultura doVale do Paraíba Paulista (18651887)". Revista Brasielira de Economia, v. 56, n. 1, p. 147-170, JAN-MAR, 2002.

MENDONÇA, Sonia Regina de. O ruralismo brasileiro: 1888-1931. São Paulo : Editora Hucitec, 1997.

MORAES, Maria L. Paiva Melo. Atuação da firma Theodor Wille \& Cia. no mercado cafeeiro do Brasil, 1844-1918. São Paulo: FFLCH, 1988 (Tese de Doutorado). 
PAZ FONTENLA,Vicente. Bancos (teoría e realidade). Rio de Janeiro: Atlas, 1944.

PINHEIRO, Marcos Antonio Henriques. Cooperativas de Crédito História da evolução normativa no Brasil. Brasília: Banco Central do Brasil, 2008.

PIRES, Anderson e ALMICO, Rita de C. "Crédito e finanças em uma sociedade cafeeira”. História e Economia: revista interdisciplinar. São Paulo: BBS,V. 4 n. 2, 2008.

PERISSINOTO, Renato M. Classes dominantes e hegemonia na República Velha. Campinas: Ed. Unicamp, 1994.

ROCHA, Alfredo. Caixas economicas e o credito agrícola, Rio de Janeiro: Imprensa Nacional, 1905.

SAES, Flávio A. M. de. "Estado e sociedade na Primeira República: a questão monetária e cambial durante a crise cafeeira (1896-1906)". Revista Brasileira de História, v.01, $\mathrm{n}^{\circ} 02,1981$. 1986.

. A grande empresa de serviços públicos na economia cafeeira. São Paulo: Hucitec,

. Crédito e bancos no desenvolvimento da economia paulista 1850 - 1930. São Paulo: IPE/USP, 1986.

SOARES, José Julio. Idéas cooperatistas. Belo Horizonte: Salesiano, 1914.

STEIN, Stanley J. Grandeza e Decadência do Café no vale do Paraíba. São Paulo: Ed. Brasiliense, 1961.

TAUNAY,Affonso de E. História do café no Brasil. Rio de Janeiro: Inst. Nacional do Café, 1941, v. 11.

TEODORO, R. S. O Crédito no Mundo dos Senhores do Café: Franca 1885-1914. Campinas (Dissertação de Mestrado), 2006.

TORELLI, Leandro S. A Defesa do Café e a Política Cambial: Os Interesses da Elite Paulista na Primeira República (1898-1920). Campinas: IE/Unicamp, 2004 (Dissertação de mestrado). 
